Europe's Journal of Psychology 2/2009, pp. 82-95

www.ejop.org

\title{
Age and motives for volunteering: Further evidence
}

\author{
María Celeste Dávila \\ Complutense University of Madrid \\ Juan Francisco Díaz-Morales \\ Complutense University of Madrid
}

\begin{abstract}
This work has explored the socioemotional selectivity theory (Cartensen, 1995) with the purpose of evaluating how people selectively optimize their activities involving social investments as they increase in age, investing more in self-relevant and emotionally meaningful goals. Specifically, the purpose of this study was to test hypotheses derived from the socioemotional selectivity theory regarding the effects of age on motives for volunteering. The Volunteer Functions Inventory (Clary et al., 1998) was completed by 214 volunteers affiliated with different organizations. Results indicated that, as age increases, career, understanding and making friends volunteer motivations decrease, while social and values volunteer motivations increase. Possible implications for volunteer management in organizations are analyzed.
\end{abstract}

Keywords: motivations, age, volunteerism, socioemotional selectivity theory.

In recent years, psychosociological studies about volunteerism have increased, and several theoretical models to explain volunteerism have been developed (see for example, Omoto \& Snyder, 1995, 2002; Callero, Howard, \& Piliavin, 1987; Grube \& Piliavin, 1996; Piliavin \& Callero, 1991). The motivation to volunteer is a factor in some theoretical models, and it is considered important for understanding participation in volunteer services (Black \& Di Nitto, 1994; Clary \& Snyder, 1991; Omoto \& Snyder, 1990; and Penner \& Finkelstein, 1998). Presently, the functional theory of motivation to volunteer is the most important approach to understanding motivation to volunteer. Clary and Snyder (1991) designed this theory to explain the different types of motives that can determine participation in volunteer services. This approach holds that different individuals may participate in the same volunteer work for very 
different reasons, and volunteering can satisfy different motives for the same individual at different times. Based on this theory, Clary and Snyder (1999) identified six primary motives: protective (to reduce negative feelings), values (to express or act on important values), social (to strengthen social relationships), understanding (to learn about the world), career (to gain career-related experience) and enhancement (to enhance self-esteem). Okun and Schultz (2003) included a new motivation not described by Clary and Snyder: "making friends". Whereas social motive show the desire to sustain existing friendships as a motive for volunteering, the making friends motive shows the desire to make new friends.

Age differences in motivation to volunteer have thus far rarely been analyzed (Black \& Jirovic, 1999; Okun \& Schultz, 2003). A review of some studies showed that in some cases there were similarities between younger and older volunteers (e.g, Black \& Jirovic, 1999; Clary \& Snyder, 1999; Marriot Seniors Volunteerism Study, 1991), while other studies have found that younger volunteers give more importance to career motives (Black \& Kovacs, 1999; Clary \& Snyder, 1999; Okun, Barr \& Herzog, 1998; Okun \& Schultz, 2003) and to protective motives for volunteering (Black \& Kovacs, 1999; Ferrari, Loftus \& Pesek, 1999). However, older volunteers give more importance to social motives (Greenslade \& White, 2005; Okun, Barr \& Herzog, 1998; Okun \& Schultz, 2003; Zeweigenhaft, Armstrong, Quintis \& Ridick, 1996).

According to Funes (1999), the life stage of a person affects the articulation of all such variables with respect to one's predisposition and decision to act. The accumulation of experiences with the passing of time and changes in perceived social conditions across life stages contribute to these age effects. Life course studies (e.g., Elder, Johnson \& Crosnoe, 2003) indicate that the meaning of roles and activities changes across life stages. Oesterle, Kirpatrick and Mortimer (2004) indicated that determinants of volunteerism are life-stage-specific; for example, they found that involvement in full-time work and family reduces rather than promotes volunteerism during young adulthood. Additionally, marriage and income were found to be unrelated to volunteering during the early adult years, although they promote volunteering in adult samples overall. Omoto, Snyder and Martino (2000) found that younger adults engage in volunteer services to fulfil motivational agendas related to interpersonal relationship considerations, whereas older adults seek to fulfil motivational agendas related to service and community obligation concerns. Volunteering is an activity that can be performed over a wide span of the life course, but its meaning may change predictably with changes in roles and agendas over a person's lifetime (Omoto, Snyder \& Martino, 2000). 
According to the theory of socioemotional selectivity (see Cartensen, 1995), people become more selective with their social investments as perceived time left to live becomes more limited. Through selective optimization, the activities least important are neglected on behalf of those activities with more subjective meaning; people invest more in self-relevant and emotionally meaningful goals. Past studies have found that chronological age is inextricably and negatively associated with perceived amount of time left in life, and the prioritization of goals is different across life stages (see, for example, Carstensen, Isaacowitz \& Charles, 1999; Fung, Carstensen \& Lutz, 1999). Fung, Cartensen and Lang (2001) have showed that the salience of social goals related to knowledge seeking decreases across adulthood, whereas the salience of social goals related to emotional gratification increases with age. Also, as people age, they have a greater preference for familiar as opposed to new social partners.

Volunteerism is recognized as an important source of sociability, satisfaction, and self-validation over the life course (Hendicks \& Curtler, 2004), and people volunteer for different reasons and motives, depending of their life stage or their perceived time left to live. In connection with the theory of socioemotional selectivity, career and understanding motives will be associated with knowledge seeking. Enhancement (focus promoting positive affect) and protective (focus reducing negative affect) motives will be associated with emotional gratification. With regard to values motive, acting on deeply held beliefs can contribute to obtain a sense of purpose for their lives and it can enhance emotional gratification.

The aim of this study was similar to that of Okun and Schultz's study: to test hypotheses regarding relations between age and motives for volunteering derived from socioemotional selectivity theory. The present study tries to contribute new evidence by studying a Spanish volunteer sample and carrying out some additional analyses, such as controlling the effect of length of service. Given that the strength of the motives of volunteers change over the years spent in an organization, it's important a control for length of volunteer service (Clary \& Snyder, 1991).

According to the socioemotional selectivity theory, the hypotheses to test are: (1) career and understanding motives will be lower among older volunteers than among younger volunteers, (2) enhancement and protective motives will be higher among older volunteers than among younger volunteers, (3) older volunteers will have lower making friends motivation (desire to make friends) and higher social motivation (desire to sustain existing friendships) than younger volunteers, and (4) older volunteers will have higher values motivation than younger volunteers. 
Method

Sample

Two hundred fourteen volunteers affiliated with 23 non-governmental organizations participated in this study. The mean age was 37.52 years ( $S D=17.51$ ), and $67.8 \%$ of the participants were women. With regard to education levels, $12.6 \%$ of participants had completed only primary studies, $31.8 \%$ secondary studies, and $55.1 \%$ university studies. The sample was split into six different age groups: 16-25 ( $N=78), 26-35(N=40)$, $36-45(\mathrm{~N}=26), 46-55(\mathrm{~N}=31), 56-65(\mathrm{~N}=19)$ and more than 66 years $(\mathrm{N}=20)$.

Instruments

Motivations for volunteering. A Spanish adaptation (Dávila \& Chacón, 2003) of the Volunteer Functions Inventory (VFI) created by Clary et al. (1998) was used. The questionnaire is composed of 30 items with a seven-point Likert-scale response format, ranging from 1 (not at all important) to 7 (extremely important). The scores for each of the six motivation scales identified by Clary et al. (protective, values, social, understanding, career and enhancement) were formed by averaging the responses to the five items that assessed each motive, with the exception of enhancement motive; its score was formed by averaging the responses to only four items. In the present study, we have used Okun and Schultz's (2003) procedure to calculate the score of making friends. Whereas items on the social scale assess the desire to sustain existing friendships as a motive for volunteering, the remaining enhancement item ("volunteering is a way to make new friends") assesses motivation to make new friends. Reliability (Cronbach's alphas) for the six scales ranged from 0.91 (career) to 0.61 (values).

Length of service. The volunteers were asked about the number of months they had spent in the organization.

Procedure

The conditions of questionnaire administration were agreed upon previously with each organization to reduce interference with regular functioning; in the majority of cases, a representative of the organization distributed and collected the questionnaires.

Results

To check hypothesis we carried out different types of analysis. First, we conducted descriptive analyses of the motivations using age group. Second, we carried out a 1- 
way MANOVA with age as between-subjects factor (6 levels) and scores on the 7 motives for volunteering scales as the vector of dependent variables. To control length of service we carried out a MANCOVA with it as a covariate. Third, we calculated correlations and multiple regression analyses for motivations and age.

Descriptive analyses of motivations with age group

The means and standard deviations for each motivation and age group are presented in Table 1. The most important motivations across all age groups are understanding and values. Up to 35 years old, understanding is the most important motivation for volunteering, but, after this age, the most important motivating factor is expressing or acting on values. All age groups also consider the protective and career motivations as less important to volunteering. From 26 years old onward, the career motivation is the least important. The relative importance of the remaining motivations changes for each age group. Up to 45 years of age, making new friends is more important than social and enhancement motivations, but, from this age, making friends is the least important of these three motivations. In Figure 1, the variations of motivations by age group are showed.

Table 1.

Descriptive Statistics for Motivations by Age Group $(N=214)$.

\begin{tabular}{|c|c|c|c|c|c|c|c|}
\hline Motivations & $\begin{array}{l}\text { Age } \\
\text { Group }\end{array}$ & $M$ & $S D$ & Motivations & $\begin{array}{l}\text { Age } \\
\text { Group }\end{array}$ & $M$ & $S D$ \\
\hline \multirow[t]{6}{*}{ Protective } & 1 & 2.95 & 1.35 & Understanding & 1 & 5.89 & 0.85 \\
\hline & 2 & 2.83 & 1.36 & & 2 & 5.71 & 1.11 \\
\hline & 3 & 2.51 & 1.32 & & 3 & 5.54 & 0.85 \\
\hline & 4 & 3.01 & 1.45 & & 4 & 5.36 & 1.46 \\
\hline & 5 & 3.17 & 1.62 & & 5 & 5.34 & 1.27 \\
\hline & 6 & 2.91 & 1.37 & & 6 & 5.04 & 1.38 \\
\hline \multirow[t]{6}{*}{ Values } & 1 & 5.74 & 0.86 & Make Friends & 1 & 4.90 & 1.70 \\
\hline & 2 & 5.59 & 0.78 & & 2 & 4.50 & 1.84 \\
\hline & 3 & 5.76 & 0.80 & & 3 & 3.96 & 1.99 \\
\hline & 4 & 5.70 & 1.35 & & 4 & 3.74 & 2.05 \\
\hline & 5 & 6.41 & 0.54 & & 5 & 4.12 & 2.45 \\
\hline & 6 & 6.52 & 0.59 & & 6 & 3.23 & 2.44 \\
\hline \multirow[t]{6}{*}{ Career } & 1 & 3.81 & 1.52 & Enhancement & 1 & 4.15 & 1.39 \\
\hline & 2 & 2.80 & 1.52 & & 2 & 4.07 & 1.51 \\
\hline & 3 & 1.52 & 1.10 & & 3 & 3.82 & 1.64 \\
\hline & 4 & 1.93 & 1.58 & & 4 & 4.51 & 1.36 \\
\hline & 5 & 1.37 & 0.68 & & 5 & 4.58 & 1.70 \\
\hline & 6 & 1.40 & 0.57 & & 6 & 3.86 & 1.82 \\
\hline \multirow[t]{6}{*}{ Social } & 1 & 4.33 & 1.38 & Total & 1 & 27.09 & 5.26 \\
\hline & 2 & 3.94 & 1.63 & Motivation & 2 & 24.92 & 5.51 \\
\hline & 3 & 3.54 & 1.22 & & 3 & 23.12 & 4.65 \\
\hline & 4 & 4.27 & 1.21 & & 4 & 24.31 & 4.54 \\
\hline & 5 & 4.64 & 1.52 & & 5 & 26.74 & 4.68 \\
\hline & 6 & 4.86 & 1.47 & & 6 & 23.20 & 4.24 \\
\hline
\end{tabular}




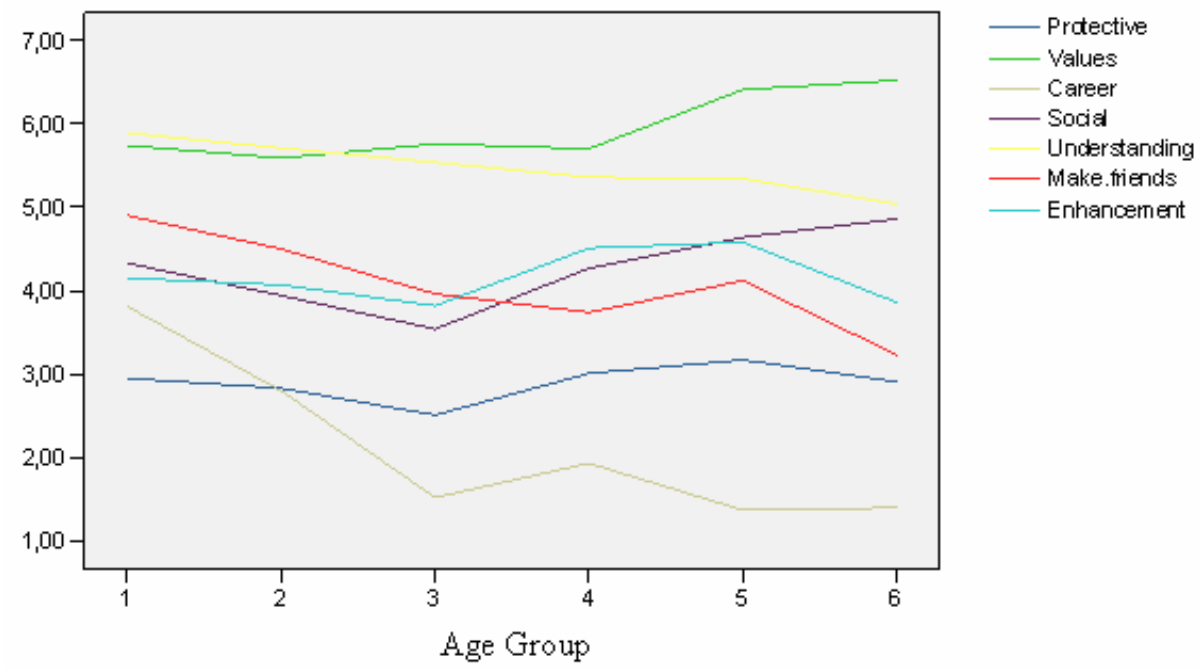

Figure 1.

Mean of motivations by age group.

\section{MANOVA and MANCOVA}

In order to check if there were significant differences in motivation across age groups, we carried out a MANOVA. There were significant differences for the following motivations: making friends $(F(5,209)=3.19 ; p<0.01)$; values $(F(5,209)=3.24$, $\mathrm{p}<0.01)$; career $(F(5,209)=17.42, p<0,01)$; social $(F(5,209)=2.52, p<0.05)$ and understanding $(F(5,209)=3.87, p<0.01)$. Post-hoc multiple comparisons (Bonferroni test, $p<0,05$ ) indicated that younger volunteers (Group 1, 16-25 years) gave more importance $(M=4.90)$ to making friends than older volunteers (Group 6, +66 years, $M=3.23$ ). Additionally, older volunteers (Group $6,+66$ years) gave more importance $(M=6.52)$ to the values motive than younger volunteers (Group 2, 26-35 years, $M=5.59$ ). Younger volunteers gave more importance (Group 1, 16-25 years, $M=3.81$; Group 2, 26-35 years, $M=2.80$ ) to the career motive than older volunteers (Group 3, $36-45$ years, $M=1.52$; and Group $6,+66$ years, $M=1.40$ ). When compared only with Group 1: Group 2, 16-25 years, $M=2.80$; Group 4, 46-55 years, $M=1.93$, and Group 5, $56-65$ years, $M=1.37$. About understanding, younger volunteers (Group 1, 16-25 years, $M=5.89$ ) gave more importance to this motive than older volunteers (Group 6, +66 years, $M=5.04$ ). Post-hoc multiple comparisons did not indicate significant differences among age groups for social motive.

When we carried out a MANCOVA using length of service as a covariate, we found that this variable had a significant effect on social motive $(F(5,209)=11,28 ; p<0.01)$, but the effects of age did not change significantly. The relationship between length of service and social motive did not affect the relationship between age and motivations. 
Correlations and multiple regression analyses across motivations and age

Age had a significant and negative relationship with the making-friends motivation $(r=-0.248$, $p<0.01)$, career motivation $(r=-0.532, p<0.01)$, and understanding motivation $(r=-0.265, p<0.01)$. However, age was significantly and directly related to the values motivation $(r=0.218 ; p<0.01)$.

To study the relationships between age and motivation in depth, we performed multiple regression analyses, controlling statistically for the other motives. Each motive was regressed separately on the other six motives scores and age.

Age was a significant predictor of four of the seven motives scores (see Table 2). Age accounted for $2 \%$ of the variation in the protective motive, $2.1 \%$ of the variation in the values motive, $28.6 \%$ of the variation in the career motive, and $9.4 \%$ of the variation in the understanding motive. Age was a significant inverse predictor of the understanding and career motivations. Age was a significant positive predictor of the protective and values motivations.

Table 2.

Sumary of Multiple Regresión Analises of Motivation to Volunteer. Scores $(N=214)$.

\begin{tabular}{ccccc}
\hline Motivations & $\mathbf{R}_{\text {Covariates }}$ & $\mathbf{R}_{\text {Ag }}$ & $\mathbf{F}_{\text {Age }}$ & $\boldsymbol{\beta}_{\text {Age }}$ \\
Protective & 0,501 & 0,020 & $7,276^{* * *}$ & 0,173 \\
Values & 0,334 & 0,021 & $5,348^{*}$ & 0,187 \\
Career & 0,129 & 0,286 & $69,405^{* * *}$ & $-0,535$ \\
Social & 0,252 & ---- & ---- & ---- \\
Understanding & 0,249 & 0,094 & $23,572^{* * *}$ & $-0,337$ \\
Make Friends & 0,352 & ---- & ---- & ---- \\
Enhancement & 0,504 & ---- & --- & --- \\
\hline
\end{tabular}

$* p<.05 . * * *<<01$

\section{Discussion}

In the present study, we have tested hypotheses derived from the socioemotional selectivity theory regarding age differences in motives for volunteering. In general, our findings are consistent with our predictions, with some exceptions.

With respect to our first hypothesis, that career and understanding motives will be lower among older than younger volunteers, a revision of the descriptive statistics of the motivations by age group shows that the understanding motive is very important throughout the life course, but it progressively loses importance with age. With regard to the career motivation, all age groups consider it to be the least important 
motivation, but, starting at 26 years of age, its absolute importance is reduced even more. The results of an MANOVA show that volunteers between 16-35 years old give significantly more importance to the career motive than other volunteers, and this age group gives significantly more importance to the understanding motive than oldest volunteers. Last, the correlations analyses show that age has a significant and negative relationship with the understanding and career motives. When we statistically control for other motives for volunteering in multiple regression analyses, we find that these relationships remain and that age has an important role in predicting the career and understanding motives, especially career. These findings are consistent with the results of Okun, Barr and Herzog (1998) and Ferrari, Loftus and Pesek (1999), for example, and with the idea that, as people age, they invest less time and energy in acquiring new learning or career-related experiences.

With regard to the second hypothesis, that enhancement and protective motives will be higher among older than younger volunteers, the results are not conclusive. Descriptive analyses show that the protective motive has little importance across all age groups, and the enhancement motive has a relatively intermediate importance for all age groups. When we statistically control for other motives for volunteering, we find that the age is a significant predictor only of the protective motive. With age, people control their internal self-regulation of emotions better. For this reason, it is not clear whether older people use volunteering as a strategy to meet their needs for emotional gratification because volunteering represents an external emotion regulation strategy (Okun \& Shultz, 2003).

For our third hypothesis, that older volunteers will have lower making friend motivation and higher social motivation than younger volunteers, the descriptive analyses show that making friends motive has an intermediate importance for all age groups. From approximately 16-45 years old, making friends is the third most important motivation, but, from 45 years old onward, this motivation lost importance. The results of an MANOVA are consistent with these data: making friends is more important to younger volunteers. We also find that age has a significant and inverse relationship with the importance of making friends, but, when we control for the effect of other motives, age is not a significant predictor of the motive to make friends. The social motive is of relatively intermediate importance in all age groups, but its importance increases starting from 46 years of age. In this case, the pattern of change is inverse compared to the motive to make friends. The rest of our results do not support the relationship between age and the social motive. These results are in line with the findings of Zeweigenhaft, Armstrong, Quintis and Ridick (1996); Okun, Barr and Herzog (1998) and Greenslade and White (2005). According to 
socioemotional selectivity theory, during youth and early adulthood (when time is usually perceived as expansive), people give more priority to meeting social goals that imply an expansion of their social horizons; that is, goals aimed at optimizing the future are prioritized. However, during adulthood and old age (when time is usually perceived as limited), emotionally meaningful goals become relatively more important, and people become more selective about their investment in social activities and relationships.

With regard to our fourth hypothesis, that older volunteers will have higher values motivation than younger volunteers, we find that the values motive is one of the most important motivations for volunteering across all age groups, but its importance is greatest from 36 years old onward. We also found significant differences in the importance of this motive between younger volunteers (26-35 years) and the oldest volunteers. Supporting our previous results, there is a positive and significant correlation between age and the values motive that continues even when we control for other motives for volunteering.

When time is perceived as limited, emotionally meaningful goals become more important. Lang and Carstensen (2002) distinguish between two subtypes of emotionally meaningful goals, one related to the regulation of emotions and one related to generativity goals, such as becoming a "keeper of the meaning" or "taking responsibility for future generations". This second subtype of goals has been found to be most prominent in later adulthood. In this sense, some studies have found stronger prosocial orientations among older adults than young adults. McAdams et al. (2000) (see Lang \& Carstensen, 2002) suggested that a strong commitment to generativity goals later in life may reflect a desire for "symbolic immortality".

Theses results are also consistent with Chacón and Vecina's (1999) findings. They found that older volunteers consider the values motive significantly more important when initiating volunteering.

In general, our results are consistent with Okun and Schultz's (2003) findings, even after controlling the length of service's effect on motives. Although it is possible to find some discrepancies with specific results (in some correlations, for example), the most important differences can be found with regard to the making friends and values motives. In previous study, age was positively related to the making friends motive, and its relation was nonlinear, but, in the present study, the relationship was negative. The values motive was unrelated to age in previous study, but, in the 
present study, there was a positive relation. These differences between studies could be due to several factors: type of organization where people are doing their volunteer service, type of task developed, etc. The principal differences may also be due to several limitations in our study and/or cultural differences. Okun and Schultz's study used Anglo-Saxon volunteers, while the present study used volunteers from Spain.

With regard to limitations, first, the studied sample was not representative of the population of volunteers in Spain, and the size of the age groups was not balanced; furthermore, the number of people was limited in some groups. The disparities among the number of participants in each age group may have adversely affected the power associated with the post-hoc pair-wise test. Second, the present study is cross-sectional; it is necessary to also conduct longitudinal studies where the evolution of sociohistoric context and its effect on volunteer motivations can be analyzed. More information about the dynamics of change in motivations through time is also necessary (Perry \& Imperial, 2001). Third, we did not examine some factors that are key to testing the socioemotional selectivity theory, for example participants' health status (poorer health is associated with perceived amount of time left in life) or future time perspective (Cartensen et al, 1999). Forth, the individuals may not be aware of their underlying motives for volunteering. Finally, how social desirability can affect reported motives is another factor that we need to control for in the future.

These results have clear practical implications. Being aware of motivational agendas can be useful when designing recruitment tailored to the profile of the volunteers a group wants to attract, matching the message to the motivation of the recipients (Omoto, Snyder \& Martino, 2000). But the most striking finding of the present study is that within all six age groups, the two motives that were rated as most important were value and understanding. Thus, regardless of age, if one were going to develop persuasive messages for volunteering, it seems that the emphasis would be on themes such as "Volunteering is a great way to express your concern for others and to learn about the world around you". Based upon the results of the present study, it does not appear to be the case that persuasive appeals to potential volunteers of different ages would need to vary in the themes that were emphasized.

On the other hand, in order to design persuasive message it is important to consider other peculiarities of each age group. For example, Fung and Carstensen (2003) 
showed that older adults prefer and remember better persuasive messages with an emotionally meaningful appeal.

To end, this study has showed that the volunteerism can be an activity that permits to satisfy very different motives over the life course. The motivations of people can change with the passing of time, but the volunteerism can fit theses changes.

\section{References}

Black, B. \& DiNitto, D. (1994). Volunteers who work with survivors of rape and battering: motivations, acceptance, satisfaction, length of service, and gender differences. Journal of Social Service Research, 20 (1-2), 73-97.

Black, B. \& Jirovic, R. L. (1999). Age differences in volunteer participation. Journal of Volunteer Administration, 7, 38-47.

Black, B. \& Kovacs, P.J. (1999). Age-related variation in roles performed by hospice volunteers. The journal of Applied Gerontology, 18(4), 479-497.

Callero, P., Howard, J.A. \& Piliavin, J.A. (1987). Helping behaviour as role behaviour: disclosing social structure and history in the analysis of prosocial action. Social Psychology Quarterly, 50 (3), 247-256.

Carstensen, L.L., Isaacowitz, D. \& Charles, S.T. ( 1999). Taking time seriously: A theory of socioemotional selectivity. American Psychologist, 54, 165-181.

Cartensen, L.L. (1995). Evidence for a life-span theory of socioemotional selectivity. Current Directions in Psychological Science, 4, 151-156.

Chacón, F. \& Vecina, M.L. (1999). Motivaciones del voluntariado que trabaja con enfermos de SIDA o Cáncer. Psykhe, 8(1), 125-131.

Chacón, F., Vecina, M.L. \& Dávila, M.C. (2007). The three-stage model of volunteers' duration of service. Social Behavior and Personality: An international Journal, 35 (5), 627 642.

Clary, E.G. \& Snyder, M. (1991). A functional analysis of altruism and prosocial behavior: The case of volunteerism. Review of personality and social psychology, 12. 
Clary, E.G. \& Snyder, M. (1999). The motivations to volunteer: Theorical and practical considerations. Current Directions in Psychological Science, 8(5), 156-159.

Dávila, M.C. \& Chacón, F. (2003). Adaptación del inventario de funciones del voluntariado a una muestra española. Encuentros en Psicología Social, 1 (2), 22-26.

Dávila, M.C. \& Chacón, F. (2007). Prediction of Longevity of Volunteer Service: A Basic Alternative Proposal. Spanish Journal of Psychology, 10 (1), 115-121.

Davis, M.H., Hall, J.A., \& Meyer, M. (2003). The first year: Influences on the satisfaction, involvement and persistence of new community volunteers. Personality and Social Psychology Bulletin, 29, 248-260.

Elder, G.H., Johnson, M.K. \& Crosnoe, R. (2003). The emergence and development of life course theory. J.T. Mortimer \& M.J. Shanahan (Eds.). Handbook of the life course (pp. 319). New York: Kluwer Academic/Plenum Publisher.

Erez, A., Mikulincer, M., ljzendoorn, M.H. \& Kroonenberg, P,M. (2008). Attachment, personality, and volunteering: Placing volunteerism in an attachment-theoretical framework. Personality and Individual Differences, 44, 64-74.

Ferrari, J.R., Loftus, M.M. \& Pesek, J. (1999). Young and older caregivers at homeless animal and human shelters: selfish and Selfless motives in helping others. Journal of social distress and the homeless, 8 (1), 37-49.

Funes, M.J. (1999). Jóvenes y acción voluntaria: la edad como factor condicionante en la acción participativa. Estudios de juventud, 45(99), 87-92.

Fung, H.H. \& Carstensen, L.L. (2003). Sending memorable messages to the old: Age differences in preferences and memory for advertisements. Journal of Personality and Social Psychology, 85(1), 163-178.

Fung, H.H., Carstensen, L.L. \& Lutz, A.M. (1999). Influence of time on social preferences: implications for life-span development. Psychology and Aging, 14(4), 595-604.

Fung, H.H., Cartensen, L.L. and Lang, F.R. (2001). Age-related patterns in social networks among European Americans and African Americans: Implications for socioemotional selectivity across the life span. International Journal of Aging and Human Development, $52,185-206$. 
Greenslade, J.H. \& White, K.M. (2005). The prediction of above-average participation in volunteerism: a test of the theory of planned behaviour and the volunteers functions inventory in older Australian adults. The Journal of Social Psychology, 145(2), 155-172.

Grube, J. \& Piliavin, J.A. (1996). Role-identity, organizational commitment, and volunteer performance. Paper presented at the annual meeting of Society for the psychological study of social issues. Miami: Ann Albor.

Hendricks, J. \& Curtler, S.J. (2004). Volunteerism and sociemotional selectivity in later life. The Journals of Gerontology, 59B(5), 251-257.

Lang, F.R. \& Carstensen, L.L. (2002). Time counts: Future time perspective, goals, and social relationships. Psychology and Aging, 17(1), 125-139.

Marriot Seniors Living services (1991). Marriott seniors volunteerism study. Washington, DC: Author.

Oesterle, S., Kirpatrick, M. \& Mortimer, J.T. (2004). Volunteerism during the transition to adulthood: A life course perspective. Social Forces, 82(3), 1123-1149.

Okun, M.A. \& Schultz, A. (2003). Age and motives for volunteering: Testing hypotheses derived from socioemotional selectivity theory. Psychology and Aging, 18(2), 231-239.

Okun, M.A., Barr, A. \& Herzog, A.R. (1998). Motivation to volunteer by older adults: a test of competing measurement models. Psychology and Aging, 13(4), 608-621.

Omoto, A. M. \& Snyder, M. (1990). Basic research in action: Volunteerism and Society's response to AIDS. Personality and Social Psychology Bulletin, 16, 152-165.

Omoto, A. M. \& Snyder, M. (1995). Sustained helping without obligation: motivation, longevity of service, and perceived attitude change among AIDS volunteers. Journal of Personality and Social Psychology, 68 (4), 671-686.

Omoto, A.M. \& Snyder, M. (1993). AIDS volunteers and their motivations: theoretical issues and practical concerns. Nonprofit Management and Leadership, 4(2), 157-175.

Omoto, A.M., Snyder, M. \& Martino, S.C. (2000). Volunteerism and the life course: Investigating age-related agendas for action. Basic and applied social psychology, 22(3), 181-197. 
Penner, L.A. \& Finkelstein, M.A. (1998). Dispositional and structural determinants of volunteerism. Journal of Personality and Social Psychology, 74 (2), 525-537.

Perry, J.L. \& Imperial, M.T. (2001). A decade of service-related research: a map of the field. Nonprofict and voluntary sector quarterly, 30(3), 462-479.

Piliavin, J.A. \& Callero, P.L. (1991). Giving Blood: The development of an Altruisticlidentity. Baltimore: Johns Hopkins University Press.

Warburton, J., Ferry, D.J., Rosenman, L.S. \& Shapiro, M. (2001). Differences between older volunteers and nonvolunteers. Research on aging, 23(5), 586-605.

Zeweigenhaft, R.L., Armstrong, J., Quintis, F. \& Ridick, A. (1996). The motivations and effectiveness of hospital volunteers. Journal of Social Psychology, 136, 25-34.

About the authors:

María Celeste Dávila is Ph.D on Psychology and lecturer in Social Psychology Department (Faculty of Politic Sciences and Sociology. Complutense University of Madrid. Spain). Her main research topic is prosocial behavior.

E-mail: mcdavila@cps.ucm.es

Juan Francisco Díaz-Morales is Ph.D on Psychology and lecturer in Department of Individual Differences and Work Psychology (Faculty of Psychology. Complutense University of Madrid. Spain). His main research topics are procrastination, temporality, and cronopsychology. 